\title{
A ESTRUTURA EDUCACIONAL COMO REFLEXO DA CULTURA BRASILEIRA
}

\author{
Núncia Maria Santoro de Constantino*
}

É muito comum falar-se em sistema educacional brasileiro, o que, sob vários aspectos, não é correto.

Comecemos, então, por algumas definições.

Entende-se por sistema o conjunto de elementos, materiais ou não, que constituem um todo organizado ou coordenado para o alcance de determinado fim.

Nesta perspectiva, sistema educacional é um conjunto de ações coordenadas para promover a Educação que, por sua vez, visa promover o homem.

O Professor Dermeval Saviani, (1975), parte do pressuposto de que, no Brasil, não há sistema educacional. Seus argumentos dizem respeito, em primeiro lugar, à quantidade de soluções importadas ou transplantadas, logo soluções não brasileiras aos problemas educacionais.

Em segundo lugar, Saviani diz que o ato de sistematizar pressupõe uma consciência refletida, sendo um ato intencional e, por isso, ato que requer planejamento. No Brasil não houve, sempre, um efetivo planejamento a nível nacional.

Em terceiro lugar, o ato de sistematizar engloba a idéia de conjunto assim como de coerência entre os elementos do conjunto. Então, sistema é um conjunto coerente. Ora, no Brasil a estrutura nem sempre formou um conjunto coerente.

O que sempre existe, no Brasil, é uma determinada estrutura formada por diversos sistemas educacionais.

Justificando-se assim a primeira expressão do título do presente trabalho, trata-se de abordar a questão da Educação brasi- 
leira como reflexo de cultura. Para isso, analisa-se a evolução desta Educação em termos formais, de modo a refletir o que a maioria denomina, com equívoco, sistema educacional.

A educação brasileira começou com a catequese, tendo na sua origem, obviamente, um caráter predominantemente religioso.

Os primeiros educadores foram seis jesuítas que, chefiados por Manuel da Nóbrega, chegaram com o primeiro governador geral Tomé de Souza.

A Companhia de Jesus era instituição recente; fora fundada em 1534. Tinha como objetivos combater a heresia, propagar a fé e difundir o evangelho. Possuía, como sabemos, uma rígida disciplina e seus membros eram caracterizados pela grande cultura literária.

Os jesuítas vieram para o Brasil enviados por D. João III, mas seu compromisso maior era com a Igreja e com os supremos interesses da religião. Pretendiam, portanto, o domínio das almas e, uma vez em solo brasileiro, iniciaram seu trabalho com pres teza.

Quinze dias após sua chegada, e enquanto se fundava a cidade de Salvador, os jesuítas já faziam funcionar uma aula de ler e escrever. O primeiro mestre-escola dos brasileiros foi Frei Vicente Rijo ou Rodrigues que ensinou durante 50 anos.

De 1549 a 1559, o Pe. Manuel da Nóbrega e o Pe. Luiz da Grã, sucessor do primeiro no cargo de Provincial, vão fundando escolas em Porto Seguro, Espírito Santo e São Vicente,onde, desde 1549, funcionou um seminário-escola que correspondia aos atuais estabelecimentos de nível médio.

Nóbrega orientou seus subordinados para que construíssem casas e ensinassem moços dos gentios e também dos cristãos. Quando morreu, em 1570, havia cinco escolas de instrução elementar: Porto Seguro, Ilhéus, Espírito Santo, São Vicente e São Paulo de Piratininga que foi fundada em 1554, com a presença de Anchieta.

Além das escolas elementares havia, em 1570, os colégios do Rio de Janeiro, de Pernambuco e da Bahia. Nos colégios funcionavam classes de primeiras letras, classes de Latim e classes de 
Humanidades. Uma classe de Humanidades incluía estudos de Latim, estudos de Grego e de Literatura Clássica. Pode-se comparar um curso de Humanidades a um segundo ciclo de ensino secundário.

José de Anchieta ensinou Latim e Humanidades no colégio de Piratininga e preparou meios didáticos para os meninos índios: livros, canções, peças teatrais, a primeira gramática na língua indígena. Estes meios acabaram sendo adotados nos outros colégios dos jesuítas, onde ensinavam religião, leitura, escrita, matemática, língua portuguesa, danças portuguesas, canto e execução musical na flauta.

As escolas eram fixas ou ambulantes, sendo que estas perambulavam pelas aldeias.

Com as escolas dos jesuítas surgiu no Brasil uma educação literária de fundo religioso, organizada em conseqüência da Reforma Protestante e da Reforma Católica. Desenvolveu-se uma educação voltada, sobretudo, para a propagação da fé, pois a Igreja Católica necessitava ocupar novos espaços que compensassem aqueles perdidos na Europa.

Foi também pelas escolas primárias jesuíticas, com suas aulas de gramática, que o português tornou-se a língua geral dos índios que aprendiam através dos seus curumins que, por sua vez, aperfeiçoavam pelo convívio com os filhos dos reinóis e com os órfãos trazidos de Lisboa pelos padres.

Não há dúvida de que os jesuítas, ao transplantarem para o Brasil um tipo de cultura coerente com sua concepção de vida e de mundo, acabaram sendo agentes da desintegração dos valores nativos. Anchieta, numa das suas cartas, escrevia que pretendia "levar os meninos índios a abominarem os usos de seus progenitores".

Durante dois séculos, os jesuítas foram os guias intęlectuais da Colônia, lutando para assegurar a posse e a unidade do poder espiritual e, assim, auxiliando a coroa portuguesa na tarefa de resguardar a propriedade territorial. Manuel da Nóbrega, acompanhando Mem de Sá, intervinha contra os invasores franceses; Antônio Vieira incentivava, nos seus sermões, a reação contra os invasores holandeses. 
Como vimos anteriormente, os jesuítas não se detiveram no ensino fundamental; em 1575, no Colégio da Bahia, já conferiam graus de bacharel. Em 1578, passaram a conferir as primeiras láureas de mestre em artes.

O grau de bacharel incluía estudos de gramática, humanidades e retórica. Mestre em Artes era láurea para filósofos, com estudos de lógica, metafísica geral, matemáticas, ética, teodicéia, ciências físicas e naturais.

Havia um terceiro curso - Teologia e Ciências Sagradas que se instalou em Seminários Maiores, para a formação de novos jesuítas, depois de 1599.

Já a partir de 1580, religiosos de outras ordens, como carmelitas, beneditinos e franciscanos, auxiliavam a obra educativa dos jesuítas.

A formação religiosa realizada nos Seminários Maiores era excelente e os padres formados no Brasil, como Antônio Vieira, tornavam-se admirados pela cultura inclusiva na Metrópole.

Bacharéis e Letrados, assim como religiosos, eram formados no Brasil pelos jesuítas que preparavam os moços da elite, quando estes preferiam cursar Direito ou Medicina, o que só poderia ser feito na Europa.

A Universidade de Coimbra passou a exercer, por isso, um papel fundamental na formação das elites. A Metrópole centralizava os estudos superiores na sua velha Instituição e, assim, pretendia quebrar os impulsos de independência ou, simplesmente, aportuguesar.

No século XVIII, pouco antes da sua expulsão, os jesuítas fundaram no Brasil quatro seminários para o clero secular, o da Paraíba, o do Pará, o do Maranhão e o de Paranaguá. Com estes estabelecimentos, passaram a formar padres-mestres e capelães de engenho.

Ora, depois da expulsão dos jesuítas por Pombal, estes padres-mestres e estes capelães de engenho ficaram sendo os continuadores da tradiçăo de ensino jesuítico.

Vê-se, então, que os jesuítas exerceram autoridade, no início, através da educação dos sinhozinhos nos colégios e que, de- 
pois, continuaram exercendo influência cultural junto às elites, através dos padres-mestres e dos capelães de engenho.

A Metrópole, durante dois séculos, confiara a educação da colônia à Companhia de Jesus e recebeu, com isso, uma grande obra de penetração e de colonização. À margem do sistema educacional jesuítico, a metrópole só contribuiu com a criação de escolas de artilharia e de construção naval na Bahia e no Rio de Janeiro, fundadas respectivamente em 1699 e 1738.

Fernando de Azevedo (1971, p. 539) escreve:

\begin{abstract}
"Por melhor que fosse a organização do ensino jesuítico e por seguros e eficientes que fossem os seus métodos, com que se cobriram de glórias por toda parte como humanistas, é certo que, praticados dentro de um sistema de ensino único, excessivamente literário e retórico, sem o estímulo de influências renovadoras, tenderam à uniformidade $e$ à estagnação e não ficaram ineficazes para a erradicação de toda atividade livre e criadora do espírito."
\end{abstract}

O ensino dos jesuítas impeliu as elites dirigentes para as letras e desenvolveu, desde muito cedo, o gosto que ficou antológico pelo diploma de bacharel.

Não se pode esquecer que o jesuíta preocupou-se com a lavoura e com a indústria, mas só na medida em que estas atividades serviam para a construção e manutenção de suas aldeias, colégios e igrejas.

Já nas missões jesuíticas, fora da autoridade real portuguesa, o preparo profissional foi muito mais intenso na formação da mão-de-obra indígena.

Ainda que descuidando de forma quase absoluta do preparo de atividades essenciais para o desenvolvimento da Colônia, como agricultura e indústria, pode-se afirmar que foi, em grande parte, por influência dos jesuítas que se preparou a base da Unidade $\mathrm{Na}$ cional, através da unificação da língua, da religião, enfim, da cultura - cultura universalista que caracterizou o período medieval. 
Com a expulsão dos jesuítas por Pombal, em 1759, interrompeu-se a obra desses missionários, destruiu-se um sistema de ensino e, de imediato, nada foi feito em substituição.

De um momento para outro fecharam-se todos os colégios e sobraram, em todo o Brasil, como instituições de ensino, a escola de edificações militares da Bahia, a escola de artilharia do Rio de Janeiro, três seminários para a formação de padres seculares e algumas aulas de Filosofia que funcionavam junto a conventos carmelitas e franciscanos.

Em suma, de um ensino uniformizador do intelecto, dogmático e abstrato, com métodos autoritários e consevadores, com pouquíssima abordagem científica, passou-se a quase nenhum ensino.

A pretendida reforma educacional de D. José resumiu-se, no Brasil, à criação de algumas aulas de primeiras letras, gramática, latim e grego, no Rio de Janeiro e na Bahia, treze anos depois do fechamento dos colégios jesuíticos, por volta de 1772.

Em 1774, inaugurou-se a aula régia de Latim em São João del Rei e a aula de Filosofia no Rio de Janeiro. Ainda é no Rio de Janeiro que se instalam, dois anos mais tarde, aulas de grego, hebráico, filosofia e teologia por iniciativa dos franciscanos.

Algumas aulas régias contaram, sem dúvida, com excelentes professores de inclinação iluminista como é o caso de Luís dos Santos Vilhena.

Em 1759, criara-se em Portugal uma Diretoria Geral de Estudos com a finalidade de implementar o ensino régio. No Brasil foram pálidos os reflexos da ação desta Diretoria: algumas pouquíssimas aulas isoladas. Era competência do órgão fiscalizar as aulas régias, mas foi impossível fazê-lo regularmente até 1800. Por essa época, o vice-rei passou a nomear, anualmente, um professor para visitar as aulas e informá-lo sobre a instrução.

Foi, portanto, só no início do século XIX que o Estado português iniciou, efetivamente, com tentativas de oficializar o ensino.

Fazendo-se uma síntese, vê-se que a unidade de sistema dos jesuítas foi substituída pela fragmentação, com as chamadas 
aulas-régias, isoladas e dispersas, mantidas por criação de imposto especial, o "subsídio literário".

O Estado não recrutou os professores dos quais necessitava, as nomeações eram feitas de acordo com os bispos e a maioria dos mestres eram ainda religiosos, isto é, padres-mestres ou capelães de engenho com formação jesuítica.

Por outro lado, a maioria dos professores leigos, segundo testemunhas da época, eram ignorantes do que pretendiam ensinar e não possuíam o menor conhecimento pedagógico.

Pelos padres e pelos capelães, os jovens brasileiros continuavam recebendo a instrução considerada inferior na Europa e que fora tão condenada por Pombal. O século das luzes, aqui no Brasil, acendeu algumas poucas lamparinas como o ensino ministrado pelo já citado Vilhena, na Bahia, em torno de 1790 ou como o ensino ministrado pelo Visconde de Cairu, professor de Filosofia e de Grego, também em Salvador, por volta de 1782.

O novo espírito filosófico e científico que inspirou a reorganização dos estudos superiores em Coimbra, pelo Marquês de Pombal, foi neutralizado, entre nós, pela escassez de mestres, pela distância entre a Direitoria Geral de Estudos e o Vice-rei, pela ausência de inspeção eficaz, pelo material didático selecionado além-mar. Tudo isto serviu para destruir uma tentativa de criação de sistema educacional.

Mas, de algum modo, as reformas pombalinas alcançaram o Brasil. Isto ocorreu através da Universidade de Coimbra que, modernizada, contribuiu para a formação das elites brasileiras que começaram a aprender mais ciências da natureza e matemática, depois de 1776. Ciências da natureza reunia estudos de botânica, agricultura, zoologia, química e metalurgia. Um dos brasileiros da geração de Coimbra pós-Pombal foi José Bonifácio.

Então, entre a expulsão dos jesuítas e a vinda da família real e da corte portuguesa para o Brasil, em 1808, houve um longo período caracterizado pela desorganização do ensino colonial.

No princípio do século XIX, inicia-se uma renovação cultural e alguns reflexos atingem instituições brasileiras de ensino.

As idéias liberais e democráticas aqui penetraram em conseqüência das reformas pombalinas e, mais particularmente, da 
invasão francesa a Portugal, que desorganizou a estrutura tradicidional portuguesa, abrindo melhor caminho para a propagação das novas correntes intelectuais.

No Brasil, as teorias enciclopédicas tomam expressão mais concreta no ensino do Seminário de Olinda, fundado em 1800 pelo Bispo Azeredo Coutinho.

Foi esse seminário o primeiro e tardio reflexo, na Colônia, da grande renovação cultural que se desenvolvia na Metrópole. Azeredo Coutinho estudara em Coimbra, onde usufruíra das inovações impostas pela reforma pombalina. Designado bispo de Pernambuco, tratou de imprimir no seminário as tendências pedagógicas novas: ambiente liberal com métodos mais suaves, ênfase ao ensino de ciências físicas e naturais. Também o currículo tradicional foi alterado pelo acréscimo do ensino de francês, História, Cronologia, Geometria e Desenho.

Começava-se a ensinar conteúdos que tornavam os jovens mais instrumentalizados para corresponderem às necessidades do seu meio, que era um meio de transição do patriarcalismo agrário para um meio mais urbano, já que as cidades se desenvolveram em conseqüência da exploração do ouro.

A geração educada no Seminário de Olinda foi foco de irradiação das idéias liberais e bancou para o Brasil a nova ordem européia. Foi essa geração que, de algum modo, patrocinou a Revolução Pernambucana de 1817.

Com a vinda de D. João juntamente com cerca de quinze mil acompanhantes, o Rio de Janeiro tornou-se o foco da vida inlectual no Brasil.

O clímax revolucionário europeu, favorecido pelo desenvolvimento das ciências, determinava mudança de mentalidade. A tendência estava voltada para uma certa especialização, para uma ciência limitada, para uma certa técnica; para uma profissionalização.

Houve, sem dúvida, influência dessa nova ordem na orientaçao que D. João imprimiu à criação de escolas que visavam, sobretudo, formar homens especializados e preparar pessoal capaz de atender o serviço público. 
Para provar a defesa militar, criou-se, já em 1808, a Academia da Marinha e, em 1810, a Academia Real Militar que deu origem às Agulhas Negras.

Dada a necessidade de médicos e cirurgiões para o Exército e para a Marinha, criou-se, na Bahia e no Rio de Janeiro, cursos de Anatomia e de Cirurgia.

Faziam-se necessários técnicos em Economia, Agricultura e Indústria. Fundou-se cursos para formar estes técnicos entre 1808 e 1814 também na Bahia e no Rio de Janeiro.

A Escola de Artes e Ofícios começou a funcionar em 1816 para ensinar pintura, escultura e arquitetura civil.

Chama-se atenção, entretanto, para o fato de que a obra educativa de $D$. João foi impelida pela necessidade prática e imediata, além de ser praticamente circunscrita à Bahia e ao Rio. Algumas excessões referem-se à fundação das escolas de Pernambuco, Vila Rica e Paracatu de Minas. O resto da Colônia parecia predestinado a continuar no atraso.

Proclamada a independência e fundado o Império do Brasil, a vitória dos liberais anunciava uma reorientação da política educacional impulsionada pelo desenvolvimento de um espírito nacional que deveria encarar de uma nova maneira os grandes problemas do país.

A elite culta evidencia, então, uma preocupação çom a educação popular já nos debates desenvolvidos na Assembléia Constituinte de 1823.

A Constituição outorgada pelo Imperador, em 1824, no seu artigo 179, garantia a instrução primária gratuita a todos os cidadãos. A lei de outubro de 1827, no seu artigo 10, determinava a criação de escolas de primeiras letras em todas as cidades, vilas e lugarejos. No artigo 13 da mesma lei há determinação da fundação de escolas de meninas nas cidades e vilas mais populosas. Era a primeira vez que as meninas recebiam alguma atenção do Estado.

Apesar das leis, poucas escolas foram criadas, sobretudo escolas para meninas que, em 1882, não passavam de $20 \mathrm{em}$ todo 0 país. 
Razões técnicas, econômicas e até políticas impediram que as leis fossem cumpridas.

No primeiro reinado, o ensino universitário, de algum modo, foi incentivado. Fundou-se dois cursos de Ciências Jurídicas e Sociais, um no Convento de São Francisco, em São Paulo, outro no Mosteiro de São Bento, em Olinda.

Depois da abdicação de D. Pedro I, a corrente liberal que dominava, de tendência política descentralizadora, fragmentou o ensino numa pluralidade de sistemas regionais.

O Ato Adicional de 34 transferiu para as Assembléias Provinciais a responsabilidade de regular a instrução primária e secundária. O ensino público ficou ainda mais desorganizado, com acentuadas diferenças regionais. O ensino provincial era incompleto, com exceção de São Paulo e Pernambuco.

O regime de descentralização ocasionou o extraordinário desenvolvimento do ensino particular. Para exemplificar, o Colégio Caraça, de Minas, fundado por padres lazaristas nos moldes jesuíticos, transformou-se numa das mais importantes Instituições de ensino secundário do Brasil.

Os jesuítas retornaram em 1842 e fundaram colégios na Ilha do Desterro, em Recife, São Luís, Itu, Nova Friburgo, São Leopoldo. Esses colégios adquirem grande fama.

Nesse período de descentralização, surgem liceus e aulas particulares por todo país. Alguns alcançam importância como o Liceu Paraibano, o Colégio Brandão (Cajazeiras - Paraíba), o Ginásio Baiano, os Ginásios do Rio de Janeiro e de Barbacena, fundados pelo célebre professor Abílio César Borges, o Colégio Menezes Vieira, também no Rio de Janeiro.

A única Instituição de importância criada pelo Estado, desde a abdicação até a república, foi o Colégio D. Pedro II, fundado em 1837. Caracterizou-se por ser colégio de humanidades e única Instituição de cultura e de formação geral, ainda que de nível secundário. Seu currículo tinha tendência ao ensino universalista e enciclopédico, mas apresentava, como novidade, larga concessão aos estudos científicos.

Lástima que os Estadistas do Império, marcados pela cultura jurídica e pela cultura européia, tenham estruturado um 
colégio aristocrático, voltado para a preparação de uma elite e nunca para uma educação popular.

Só por isso entende-se a grande distância cultural entre a classe dirigida, de nível extremamente baixo, e a classe dirigente-pequena elite, onde figuravam homens de requintada cultura.

Os dados oficiais divulgados em 1869 demonstram que somente a décima parte da população em idade escolar freqüentava as escolas provinciais de primeiras letras.

O ensino técnico, agrícola ou industrial, não passava de atgumas tentativas de iniciativa privada. Além do Liceu de Artes e Ofícios do Rio, por volta de 1855, havia duas escolas de comércio em todo o país. Estas logo encerraram suas atividades por falta de alunos.

Pouco tempo de existência, pelo mesmo motivo, tiveram os Institutos de Agricultura fundados no Rio, Bahia, Pernambuco, Sergipe e Rio Grande do Sul.

A mentalidade dominante era, ainda, literária e retórica, sem importar-se com a educação popular e profissional. Em 1864, para 826 alunos matriculados em Faculdades de Direito, havia uma centena de alunos matriculados em escolas comerciais e agrícolas. Estes dados demonstram que os indivíduos se afastavam das ocupações naturais do seu meio, fosse urbano ou rural, completamente deslocados da realidade econômica.

Entretanto, a cultura afastada das necessidades do meio, alheia à realidade econômica, serve como fator de mobilidade social. As faculdades sempre atraíram os jovens brasileiros que procuram ascender através do diploma.

Quanto à preparação de professores, só em 1835 foi fundada, em Niterói, a primeira Escola Normal que passou a ter importância quando foi caracterizada como colégio de moças.

Os Liceus Provinciais fracassavam por falta de recursos e de professores habilitados. Eram preteridos pelos liceus particulares. Ademais, só o Colégio D. Pedro II habilitava para a matrícula nas Faculdades. Os alunos oriundos de outras escolas secundárias, mesmo aqueles das mais distantes províncias, necessitavam prestar exames perante uma comissão do mencionado colégio. 
Em torno de 1850 foi época do maior relevo e importância do ensino particular. Época áurea do Colégio Caraça, do Colégio Dr. Kopke que buscava seus professores na Europa, do Ginásio Baiano, do Colégio Abílio, do Ateneu Sergipano e de tantos outros. Desenvolviam-se as iniciativas particulares à escassez das oficiais.

Surge plêiade de educadores que batalhavam pela renovação dos métodos de ensino, moderação nos castigos corporais, valorização do ensino de línguas modernas e ciências, aparelhamento de laboratórios. Nessa plêiade destacam-se os professores Barão de Tantphoeus, Freeze, Kopke, Pujol.

O professor Menezes Vieira fez viagens ao exterior para observar o funcionamento de colégios secundários e fundou a "escola de domingo" que consistia num curso para educação de operários. Publicou obras didáticas que, juntamente com os livros escolares de Abílio Borges - Barão de Macaúbas - , são as contribuições mais importantes do período para a renovação dos métodos de ensino secundário.

O ensino particular adquire ainda maior significação no contexto educacional através do trabalho realizado pelas ordens religiosas. Os beneditinos dirigem cursos primários e secundários; os salecianos, chegados em 1883, se especializam no ensino profissional e secundário.

Os Irmãos Maristas fundaram sua primeira escola no Brasil em 1897, Congonhas do Campo. Em 1903 criaram o Colégio de Apicucos, no Recife e o Colégio Nazaré em Belém do Pará. Seu primeiro estabelecimento de ensino no Rio Grande do Sul foi o Colégio de Bom Princípio, fundado em 1900. O Colégio Nossa Senhora do Rosário, fundado em 1904, deu origem à Pontifícia Universidade Católica do Rio Grande do Sul.

Nos fins do segundo reinado surgem as primeiras Escolas Protestantes, como a Escola Americana, fundada em São Paulo no decorrer de 1870 e a escola secundária do Mackenzie College, também em São Paulo.

O Colégio Piracicabano e o Colégio Americano de Porto Alegre foram estabelecimentos criados na década de 80 para educação de meninas e por iniciativa dos metodistas. 
A pedagogia protestante trazida para cá era de concepção norte americana, muito progressista para a época, com tendências marcantes à emancipação do espírito, ao contrário da uniformidade intelectual que caracterizou, por exemplo, o ensino dos jesuítas.

A atitude patriarcal do governo determinou que o mesmo assumisse papel de incentivador, mas não o papel de empreendedor, nas questões de ensino.

D. Pedro II sempre revelou extraordinário interesse pelas coisas do espírito. Prestigiava as escolas com visitas, oportunizava aos talentos jovens viagens de estudos ao exterior. Exerceu a função de "mecenas", auxiliando Instituições culturais como o Instituto Histórico e Geográfico, fundado na regência de Araújo Lima, o Museu Nacional, o Observatório Astronômico, a Biblioteca Nacional. Mas as suas atitudes pessoais não eram coerentes com a política imperial para a Educação. As escolas, num ritmo lento de inovação, continuavam preparando, basicamente, as elites para as profissões liberais.

As exceções encontradas no período foram as propostas do Conselheiro João Alfredo, em 1874, para a criação de escolas profissionais; a reorganização da Escola Central que passou a chamar-se Politécnica, a criação da Escola de Minas em Ouro Preto, cujas origens estão nos cursos de Metalurgia, criados por decreto pela Regência e que continuavam em decreto até então.

Outras reformas significativas estão expressas na Lei Leôncio de Carvalho, de 1879, que abriu as escolas aos negros e nos planos de reorganização do ensino, inspirados pelo Conselheiro Dantas e por Rui Barbosa, divulgados em 1882.

Lourenço Filho, analisando documentos oficiais, afirma que, durante 67 anos de Império, não há nenhuma publicação que exprima alguma corrente de pensamento pedagógico. Foi só na última Fala do Trono, em 1889, que o Imperador, finalmente, defendeu a criação de Ministério dedicado à Instrução Pública, propondo, ainda, a criação de escolas técnicas e a fundação de duas Universidades, uma no norte e a outra no sul.

Durante todo o período imperial a taxa de analfabetismo permaneceu em torno de $80 \%$. 
Feita a República, a repercussão das idéias positivistas atingiu o setor educacional.

Benjamin Constant tentou a primeira reforma à testa do curioso Ministério da Instrução, Correios e Telégrafos. Tal ministério durou só dois anos, quando os assuntos da Educação foram transferidos à pasta do Interior e Justiça.

As reformas de Benjamin Constant atingiram toda a instrução pública do Distrito Federal nos seus diferentes níveis, imprimindo-se nos currículos um cunho positivista. Foi, então, rompida a tradição do ensino literário e clássico, mas, na tentativa de acentuar estudos científicos, houve reforço ao ensino enciclopédico.

No novo regime político foi instituído o sistema de neutralidade escolar, ou seja, a proteção foi distribuída de igual modo às escolas católicas e protestantes. Era justamente 0 momento em que o Estado separava-se da Igreja.

Como foi dito antes, através das escolas protestantes, ocorreu a propagação inicial da pedagogia norte-americana que permitiu, a partir de 1871, a coeducação dos sexos, certa renovação de processos didáticos e que trouxe grande contribuição à educação feminina.

Apesar das reformas, nos primeiros anos de República, não há registro de mudança educacional expressiva. Não surgiram escolas técnicas e profissionais, tampouco tentativas sérias para a instituição de cursos de cultura livre, mais populares.

Continuavam impondo-se as escolas particulares regidas por concepções religiosas, fundaram-se mais oito faculdades de Direito, dentre as quais a de Porto Alegre. Em suma, a força da tradição impulsionava a estrutura educacional, apesar das transformações políticas

A grande mudança esperada restringiu-se, na sua plenitude, ao incremento do ensino da matemática nas Academias Militares, onde a influência positivista sempre esteve mais presente.

Sobre a relação ensino-República, Fernando de Azevedo (1971, p. 634) escreve: 
"Do ponto de vista cultural e pedagógico, a República foi uma revolução que abortou e que, contentando-se com a mudança de regime, não teve o pensamento ou a decisão de realizar uma transformação radical no sistema de ensino, para provocar uma renovação intelectual das elites culturais e políticas, necessárias às novas instituições democráticas."

Houve na República sucessivas reformas no ensino secundário, não se pode negar, mas foram tentativas muito simples, arbitrárias e regionais.

Além da já citada reforma de Benjamir, Constant, houve ainda a reforma de Rivadávia Correa, em 1911, que culminou por tirar qualquer cunho oficial do ensino secundário, incentivando o regime de livre competição.

Até 1930 não se tentou estruturar os fragmentados estudos secundários seja nas instituições públicas, particulares ou nas escolas normais.

A educação feminina havia crescido na importância com o incremento de escolas normais, colégios de freiras e escolas protestantes.

Em São Paulo, para onde se deslocara o eixo da vida econômica, a instrução progrediu nos seus diversos níveis e modalidades. Para isso contribuíram a imigração e conseqüente atividade dos imigrantes, o desenvolvimento da lavoura cafeeira e conseqüente industrialização. Lá o ensino foi modernizado com transformações na formação de professores, com utilização de técnicas de ensino norte-americanas. Criaram-se escolas normais, vários Grupos Escolares, escolas de Agricultura e Comércio, Escola de Engenharia no Mackenzie College.

Nos outros estados, a mentalidade jurídica voltada para as letras, para a política e para a administração continuou prejudicando o ensino técnico-científico que foi relegado ao plano secundário. Na primeira década do nosso século, houve algum incentivo às escolas agrícolas. Foi quando se fundou, no Rio Grande do Sul, o Instituto Borges de Medeiros, de agronomia e veterinária. 
As reformas a nível federal, simples esboços como a de Benjamin Constant, Epitácio Pessoa, Carlos Maximiliano ou Rocha Vaz, não chegaram a provocar alterações na estrutura do ensino até 1914. Mas as variações na população, a evolução da vida econômica em conseqüência do surto industrial que se verificou com a guerra, foi isto que ocasionou transformações na Educação.

Podemos dizer que as transformações educacionais que se impuseram no pós-guerra são decorrentes das pressões exercidas pela opinião pública que fora sacudida. Note-se que as revoltas de 1922 e 1924 foram acompanhadas de interesse e simpatias populares. Havia o desenvolvimento de uma mentalidade revolucionária que teve sua culminância na Revolução de 30.

Percebe-se que, após a Primeira Guerra Mundial, chega ao Brasil a chamada "Escola Nova". Aqui foi representada por Lourenço Filho, Anísio Teixeira, Carneiro Leão, Fernando de Azevedo, Lisímaco Costa.

A preocupação desses educadores ampliara-se. Já não era considerada apenas a questão de levar o maior número possível de brasileiros à escola, mas considerava-se em muito a questão da qualidade da educação popular.

Anísio Teixeira foi nome de destaque nas transformações educacionais. Aluno de John Dewey na Universidade de Colúmbia, em 1929, passou a defender os ideais da "Escola Nova" que norteariam seu trabalho educativo, principalmente como Diretor da Instrução Pública em Pernambuco.

Para a "Escola Nova", por ele defendida, a Educação deve permanecer em contínuo processo de adaptação e desenvolvimento. Alguns princípios básicos da então nova corrente educacional podem ser definidos como:

- educação ativa, experiência direta, respeito aos interesses dos alunos;

- aprendizagem através da indução ou resolução de problemas;

- educação como preparação para a vida (pragmatismo);

- função principal de orientador da aprendizagem para o professor;

- fomento à cooperação grupal, pela escola, e não à competição individual; 
- escola democrática, com livre interação de idéias e de personalidades.

O movimento de renovação educacional teve seu ponto culminante na reforma empreendida no Distrito Federal, em 1928, e que elevou a função da escola na qual imprimiu uma direção social e nacionalista. O movimento foi, sem dúvida, ideológico e colocou o Brasil diante das maiores figuras de filósofos e técnicos em Educação.

A mudança no ensino não está dissociada da nova mentalidade que gerou o movimento Tenentista, a Semana de Arte Moderna, enfim, a Revolução de 30.

Feita a Revolução, é criado o Ministério de Educação e Saúde já no Governo Provisório e sob a direção de Francisco Campos que, mais tarde, promoveu a primeira grande reforma do ensino superior. Criaram-se Universidades com a incorporação de, pelo menos, três institutos ou faculdades.

Na escola secundária inicia-se a obrigatoriedade do ensino de Higiene, Economia Política, Estatística. Suprimiu-se a validade de exames perante bancas oficiais e a freqüência tornou-se obrigatória.

O ensino religioso facultativo foi instituído nas escolas públicas para moderar os debates entre religiosos e educadores leigos.

A Carta Constitucional de 34 estabeleceu providências no sentido de assegurar uma política nacional em matéria de Educação. A União passou a ser responsável pelo traçado das diretrizes para a Educação brasileira. Criou-se o Conselho Nacional e os Conselhos Estaduais de Educação.

Houve tentativa de democratização do ensino quando se aumentaram as matrículas para o ensino público secundário. Em 1930, as vagas eram em número de 40.000 e passaram a 160.000 em 1936.

A Constituição decorrente do golpe de Estado de 37 manteve a gratuidade e a obrigatoriedade do ensino primário e instituiu o ensino obrigatório de Trabalhos Manuais. Rompeu, de certa forma, com as tradições intelectuais e acadêmicas do país, quando 
considerou dever do Estado manter o ensino técnico e profissional. Considerou, ainda, dever das indústrias e dos sindicatos manter escolas de aprendizes para os filhos dos operários.

No período de 1937 a 1954 acentuou-se o movimento de expansão quantitativa das Universidades. Em 37 havia quatro universidades que chegaram a quinze em 53. Projetaram-se e iniciaram-se a construção das "Cidades Universitárias".

Em 1930, havia sido criado o Ministério da Educação e, em 37, as atividades de ensino haviam adquirido tal desenvolvimento que, além da reforma empreendida por Francisco Campos, fêz-se necessária outra. Foi então sancionada a lei Gustavo Capanema que reorganizou o MEC para coordenar melhor as atividades educacionais ainda dispersas. Nessa lei há três pontos que se deve considerar:

10 - tendência de racionalização administrativa;

2 ? - compreensão mais profunda das funções da Educação;

30 - projeção nacional mais ampla dos serviços do Ministério.

Em 1942 outra regulamentação, também por iniciativa de Capanema, dividiu o ensino secundário em dois ciclos: ginásio e um 2 ? ciclo que poderia ser o Clássico ou o Científico.

$\mathrm{Na}$ década dos 50 , dois importantes acontecimentos demonstram a importância crescente dos assuntos educacionais. Funda-se o Instituto Nacional de Assuntos Pedagógicos (INEP) e aparece o Centro Brasileiro de Pesquisas Educacionais, responsáveis pela formação teórica de um novo grupo de educadores.

Em dezembro de 61 foi autorizada a Universidade de Brasília, outro marco da Educação brasileira, já que foi projetada para ser uma Universidade aberta, modelo da universidade moderna.

Também em dezembro de 61 foi aprovada a Lei de Diretrizes e Bases, após 13 anos de tramitação no Congresso. As Universidades constituíram-se, então, de cinco ou mais estabelecimentos de ensino superior, com administração comum, sob forma de autarquia ou fundação, com autonomia didática, administrativa, financeira e disciplinar. A Lei de Diretrizes e Bases caracteriza-se pelo seu sentido de descentralização. 
Em novembro de 66, o governo promulgou Decreto Lei tratando de fixar normas de organização para as Universidades Federais. Os departamentos passaram a substituir as Cátedras e o Professor titular, antigo catedrático, passou a integrar um departamento.

Em julho de 68, como reflexo da crise estudantil na Europa, - MEC instituiu grupo de trabalho encarregado de planejar nova reforma do ensino e, para isso, contou com a colaboração da UNESCO. O resultado dos estudos cristalizou-se na Lei 5692/71 que pretendia disciplinar o ensino de 10 e 20 Graus. A partir dessa lei, as escolas tiverem mais liberdade para organizar currículos. Instituiu-se o primeiro grau com duração de 8 anos e os cursos profissionalizantes no $2 \%$ Grau com duração mínima de três anos.

O sistema adotado, então, continua em vigência e podemos, hoje, analisar as deficiências e distorções que se revelaram na prática. Contudo representou, num determinado momento e para vários educadores, a esperança de uma Educação voltada para os novos tempos, quando as mudanças, especialmente tecnológicas, ocorrem num ritmo frenético. Representou, num primeiro plano, a esperança de que os princípios da "Escola Nova" fossem postos em prática.

Fez-se mais uma tentativa de renovação, mas o fato é que o ideal de oportunidades educacionais para todos ainda está longe de ser uma realidade no Brasil.

Por outro lado, a qualidade do ensino oferecido é precária, na maior parte das vezes, havendo disparidade entre uns e outros estabelecimentos públicos de ensino, entre as escolas particulares e as públicas, entre umas e outras regiões do país.

O próprio Mobral, de início tão festejado, é hoje alvo de críticas principalmente no que diz respeito à relação dos meios empregados e dos parcos resultados obtidos e, ainda, do perigo que representa como aparelho ideológico de Estado.

Sentimos no dia-a-dia o peso de uma multiplicidade de problemas relativos ao ensino. Algumas das falhas constatadas são decorrentes das origens da educação brasileira, como sistemas transplantados e elitistas, tendendo ao inadequado beletrismo, 
que fizeram com que a escola não se constituísse produto do meio, harmônica com as condições e exigências criadas pela realidade sócio-econômica.

Não há escolas suficientes para atender a toda população em idade escolar, contrariando o estabelecido por lei; a baixa qualidade da instrução repercute no aproveitamento escolar e na deficiência da formação profissional, mesmo nas zonas sócio-econômicas privilegiadas. A necessidade de aproveitar-se o menor, muito cedo, como força de trabalho, aliada à instrução de baixa qualidade, determinam o grave fenômeno da evasão escolar que atinge proporções alarmantes.

O caráter seletivo da escola brasileira é outra constante e, além das razões sócio-econômicas, há ainda a questão da seleção vocacional, quando só alguns tipos de aptidão ou de inteligência são valorizados. Servindo à esse seletismo, vê-se currículos inadequados, métodos ultrapassados, incompetência entre os profissionais do magistério, seja pela escassa valorização do professor, seja pelos poucos recursos financeiros destinados à Educação.

Sem dúvida que a estrutura educacional vem representando o reflexo da cultura que se caracteriza pelo transplante de idéias e de soluções.

Num país sem filósofos é óbvio que não há produção filosófica na área educacional.

Sem diretrizes filosóficas originais, destinadas à realidade brasileira, é óbvio que essa realidade nunca será atendida na área educacional e é dramático que as possibilidades e potencialidades da nação, em termos de recursos humanos, não tenham sido aproveitadas.

\section{NOTA}

* Professora do Departamento de História da PUCRS.

\section{FONTES DE CONSULTA}

AZEVEDO Fernando de. A cultura brasileira. São Paulo, Melhoramentos, 1971. FREYRE, Gilberto. Casa grande e senzala. Rio de Janeiro, José Olympio, 1969. 
Sistema educacional como reflexo...

HOLANDA, Sérgio Buarque de. Raízes do Brasil. Rio de Janeiro, José Olympio, 1971

NISKIER, Amaldo e CARVALHO, Marlene. Educação comparada moderna. Porto Alegre, Tabajara, 1973.

SAVIANI, Dermeval. Educação brasileira: estrutura e sistema. São Paulo, Saraiva, 1975. SODRÉ, Nelson Werneck. Formação histórica do Brasil. Rio de Janeiro, Civilização Brasileira, 1976.

—. Síntese de história da cultura brasileira. Rio de Janeiro, Civilização brasileira, 1981. 